\title{
Strategies for Successful Transition into Mainstream Schools for Young Children with Autism Spectrum Disorders: A Case Study
}

\author{
Mardiyanti $^{1}$ \\ ${ }^{1}$ Faculty of Medicine and Health Sciences, Islamic State University of Syarif Hidayatullah, Indonesia \\ Corresponding author: mardiyanti@uinjkt.ac.id
}

\begin{abstract}
Background: Meeting changes can be very problematic for children with Autism Spectrum Disorders (ASDs) whereas other children may take it for granted. As a result, they may cry, get upset, scream, do hand flapping or even self-harming that shows their inability to cope with the changes and their preference of sameness and routine activities. To understand the issue of changes in children with autism, people should know the complexity of the disorders.

Purpose: This article will explain further about the strategies for successful transition into mainstream schools for young children with autism as illustrated in Jack's case study in the appendices.

Methods: A case study was conducted to one respondent. Firstly, the article will explain ASDs and its atypical characteristics of 6-years old Jack. Then it will discuss strategies to help Jack's transition process, as well as strategies to support his learning process during schooling which finally comes up with conclusion to support Jack and his family's transition into mainstream primary education.

Results: Strategies for successful transition into mainstream schools for young children with autism include using visual information and activity schedules, managing sensory overload, and building literacy skills.

Conclusion: Attractive playing can be effective strategies to build skills for successful transition of young children with autism.
\end{abstract}

Keywords: Autism Spectrum Disorders (ASD), transition strategies, children 


\section{BACKGROUND}

Meeting changes can be very problematic for children with Autism Spectrum Disorders (ASDs) whereas other children may take it for granted (Lawson, 2001; Smith, Donlan, \& Smith, 2012). Even small changes in day-to-day life can be very overwhelming for them. For instance, changing the room decoration, clothes, route, unannounced visitors and changing activities from weekday activities to weekend activities and vice versa can create confusion and anxiety. As a result of changes they may cry, get upset, scream, do hand flapping or even self-harming that shows their inability to cope with changes and their preference of sameness and routine activities (Lawson, 2001).

To understand the issue of changes in children with autism, people need to know the complexity of the disorders (Dodd, 2005). People with autism have core deficits in social communication (including speech, comprehension, tone of voice, use of body language, facial expression and gesture), social interaction (inability to understand other thought and feeling, does not understand what happen and why it is happening, inability to mix and engage with socially-accepted behaviors) and limited interest or showing stereotype behaviors (Dodd, 2005). These deficits or difficulties may put the children and their families into more difficult situation if they have to meet with significant changes in their life, for example starting new schools. Nevertheless typical development children may find it hard too to start a new school but they are less likely to show challenging behaviors as children with autism.

Every child with ASDs is unique and therefore the planning of the interventions need to be adjusted based on the needs of every individual and family (Lindgren, 2011). If one child is successfully treated with one particular intervention, the others may not necessarily be addressed by the similar intervention (Huang, 2006). Families, teachers and the environment should focus on how children learn, rather than seeing that children experience learning difficulties. This reason underlies the overriding importance of the embodiment of coping strategies for children with autism who have been studied in the previous researches. However, real description of how the strategy is implemented in actual cases is rarely discussed.

\section{OBJECTIVE}

This case study aims to explain the strategies for successful transition into mainstream schools for young children with autism.

\section{METHODS}

This article use a case study of a-6 years old Jack who has Autism Spectrum Disorders (ASDs) to analyze the possible best strategies for successful transition into mainstream schools. The case is illustrated in appendices.

\section{DISCUSSION}

\section{Understanding autism}

Autism Spectrum Disorders refers to lifelong neurodevelopment disorders with unknown etiology (Robert \& Prior, 2006) characterized by persistent impairment in reciprocal social interaction and communication, and restricted and repetitive pattern of behaviors, interest and activities (Diagnostic and Statistical Manual of Mental 
Disorders, Fifth Edition [DSM-V]; American Psychiatric Association [APA], 2013). DSM-V now only uses the term ASD to cover all the categories (autistic disorder [autism], Asperger syndrome and Pervasive Development Disorder not otherwise specified) which has been used previously under DSM-IV. There are three level of severity: level one is requiring support; level two is requiring substantial support, and level three is requiring very substantial support. In addition, the diagnosis may be followed by specifiers such as intellectual disability and co-morbid conditions such as ADHD or anxiety disorder to understand fully the person condition (Autism Spectrum Australia [ASPECT], 2012). People may refers autism as an invisible disability because apparently there is nothing different with other children until the way that someone communicates, socializes and learns to reveal the symptoms of ASDs (Verdick \& Reeve, 2012).

Jack in this case study, is having problems with social interaction and communication as he only masters two to three words which is atypical child development for six-year old (Hamaguchi, 2010). He is also reported for repeating the last words or 'echolalia' while communicates with others or when anxiety occurs. Jack may also find it difficult to interact with other people as he does not like being put in a group. He also likes sameness and refuses changing activities in particular to activity's moving from indoor to outdoor activities, gets obsess with his transport toys "Thomas the tank and friends" and shows a lack of imaginative playing as typical development child usually does. He also shows stereotype or restricted behavior such as lining up his toys. Another characteristic of autism to Jack case study is that he usually covers his ears due to his difficulties in managing sensory integration.

\section{Issue with transition}

\section{Inclusive education}

Even though children with autism prefer sameness and refuse changes, they should be introduced to significant changes which are inevitable in everyday life. Changes may bring the opportunity to a new and exciting experience, bring the benefit of stimulation and education to the children to increase their self-esteem and self-awareness as well as promote new relationships and independent performance (Smith, Donlan, \& Smith, 2012).

Jack in the case study, has already undertaken preschool setting and next term he will begin the school in a mainstream classroom which currently becomes popular choice for children with disabilities worldwide (Keane, Aldridge, Costley, \& Clark, 2012). Mainstream classroom embraces the philosophy of inclusion which means that children with disabilities including autism will be educated in the general classes with general curriculum similar to other children without disabilities (Keane et al, 2012). Studies have shown that this strategy will bring advantages and disadvantages for the children. The strategy promotes equal rights, and increases the interaction within their peers in a learning environment and thus promotes gaining appropriate social skills (Crisman, 2008; Reiter \& Vitani, 2007; Tsaputra, n.d). On the other hand, the students will also be put in high risks of more distress and fearful situation due to the exposure of sensory overload such as noisy classroom, teasing and bullying, and inability to cope with school demands, peer expectation and new routine (Humphrey \& Lewis, 2008). 


\section{Transition techniques}

Children with ASD need to be provided with the necessary skills and training to succeed in a mainstream classroom (Humphrey \& Lewis 2008; Jordan 2004). It is likely that training on social and communication skills, educating social norms, rules and expectation before transition reduce anxiety and improve their ability to function effectively into a mainstream classroom (Humphrey \& Lewis, 2008). Humphrey (2008) also recommends the introduction of predictable routine and classroom order, developing peer understanding and modifying language for communication to assist their transition.

However, to meet the most useful strategies for transition planning is likely depends on the child as each child with autism is different and one strategy which works to a child may not work to another. Dunlop et al. (2009) argued that the things need to provide for transition are: "providing information about where they have to be, who might be there, what they will or should be doing, what behavior is expected, how much they have to do, how will they know that they are finished and what they will do next' (p. 126). However, Dunlop (2009) only explained 'what' things need to do but does not explain further about 'how' to do it.

\section{Use visual information to introduce new routines}

Helping children with autism using visual support are highly recommended as the child is best learns through visualization (Dunlop et al, 2010; Marks et al, 2003). Visual supports such as pictures, cue cards, prompts, story boards, diagram and graphic schedules have been effectively useful for learning (Marks et al, 2003). Hume (2012) and Smith et al (2012) also recommended visual support such as picture and photograph which can be collected from Google image engine to introduce a new activity. Smith et al. (2012) also recommends to introduce new routines step by step, breaking the information of new routines into small pieces and using signs, sketches or scripts to help the young child transition. Smith et al (2012) strategies may help in describing the 'how' to do with transition.

In term of 'what' and 'how' to support transition, those suggestions may be helpful for Jack's transition into mainstream education. Firstly, use the school's picture or photograph then information about why he should be there, when he should be there, who might be there and what he will do there. While doing these, it can be possible to use someone's judgment to identify how much information should be given and breaking it down into several times. In addition, involving the preschool teacher to introduce the new school would be very helpful. Later on, tell the child about visiting the new school. This may need to build up very slowly by first just passing through the school; then the next day visiting the school in a quiet day and stop at the school's gate. Later on try to come in into the school and finally meet new people there. Try to involve preschool teachers and parents while visiting, or have a plan to meet Jack sister and brother in the school. It is also recommended to introduce him with a buddy who will have the same class when he starts his new school. 


\section{Using activity schedules to introduce changes between activities}

Banda, Grimmet \& Hart (2009) recommended the use of activity schedules using visual supports to anticipate transition between or within activities. The technique is almost similar with visual schedules from Hume (2012) and visual information from Smith et al (2012). The different is that activity schedules are provided in a sequential format to represent activities throughout the day, thus provide predictability of the new activities but may lead to adult's dependency (Banda et al, 2009). One example of activity schedule is picture communication symbols that consist of many pictures of activities which are arranged in order to illustrate between-activity schedule in a day. Activity schedule may be used for Jack to introduce a new routine while schooling, such as the list of activities that start from the beginning of class until finishing the class.

\section{Managing sensory deficits during transition}

Sensory overload is likely the most problem affected the child in everyday life including in the transition process (Myles, 2000). Knowing what senses he might affected by the new situation is the key to manage sensory overload. Some strategies to manage sensory difficulties are: using earplug, cards, sunglasses, hat or distraction techniques to reduce fear and anxiety (Myles, 2000; Smith et al, 2012). It is also recommended for controlling the stimulus by modifying the environment such as segmenting space for specific activity, and minimizing auditory as well as visual distractions by using visual boundaries such as using tablecloths or rugs to cover instruments in the classroom (Hume, 2012). Grandin (1995) in his personal account found the sound of the toilet flushing in his school was very painful for him. In his case, modifying the school toilet for him may be helpful.

\section{Learning strategies}

Building literacy skills become a major issue as Jack is ready for reading program. Literacy skills may also become a key for Jack to be able to communicate any message and socialize with everyone (Grether \& Pelatti, 2010). When the child develops literacy skills, the development of speaking, reading and writing occurs concurrently (Grether \& Pelatti, 2010). However, in term of communication, children with ASD often have difficulties in the development of spoken language or gestures, lack of ability to initiate or maintain conversation, have repetitive and idiosyncratic use of language and lack of pretend play. Gabriel (2002) suggests to build communicative gestures by encouraging eye contacts, reaching, grasping and giving the objects, touching or tapping objects, pushing object away, pointing, or any other controlled, purposeful and coordinated movements. Gabriel (2002) also suggests to build social communication and social interaction from the child interest either based on behavioral learning theory or developmental theory, or even combination of them. Pivotal Response Training (PRT) strategies from the behavioral principle can be employed to increase the motivation of using communicative gestures such as pointing to request the desired toys. Meanwhile, the Picture Exchange Communication System (PECS) also teaches the child with autism how to communicative using objects or sharing pictures. Researchers recommended PECS for nonverbal children with autism (Kelley, 2011). Engaging the child in back and forth turn-taking activities can increase a the child's desire to use spoken language and thus build social interaction and social communication (Gabriel, 2002). 
Building attractive play can also be a suitable strategy particularly for young children like Jack (Chandler, Christie, Newson, Prevezer, \& Venus, 2009). Children love play and playing gives the child opportunities for learning about the world in a fun way thus will develop cognitive concepts, socio-emotional skills as well as language skills (Gabriel, 2002). Chandler et al (2009) describe that attractive play involves imitation and commenting such as imitate the vocal sound from the child and commenting of what the child does while trying to attract his/her attention. Attractive plays are aimed to develop the child interaction actively so that the child gets used to shared interest, looking, listening and taking turn. In addition, playing games can build social interaction where people can use pauses within the interaction sequence to obtain a child's gestures (Gabriel, 2002).

Another strategy for reading skills comes from Grandin (1995). He suggested a visualized reading method from Miller and Miller as beneficial for some children with autism. The method introduces the word as it respective meaning. For example 'the word 'fall' has the letters falling over and the word 'run' has the letters that looks like runners' (Grandin 1995, p. 38). Those learning strategies can be maximized by involving family members as well as peer participation into the planning.

\section{CONCLUSION}

Meeting changes can create difficulties for children with autism and their family. Building strategies for successful transition is a key to support the children and their family. Transition strategies should describe the "what" and "how" in order to give clear picture about things that people should do before the changes, during the changes and after the changes. Using visual information and activity schedules are recommended as the child with autism is a visual learner and likes sameness or routine. Managing sensory overload is also important as children with autism mostly have problem with sensory processing. It is also suggested to build literacy skills as well as social communication and social interaction after Jack's transition into mainstream education. Building those skills may be effective by addressing attractive playing as young children like Jack loves playing. Furthermore, it is also suggested that teachers, families and the environment surrounding need to apply a strategic approach to children with ASD individually, especially when they enter a new school environment.

\section{REFERENCES}

American Psychiatric Association. (2013). Diagnostic and statistical manual of mental disorders-fifth edition (DSM-V). $5^{\text {th }}$ ed. Washington DC.

Chandler, S, Christie, P, Newson, E, Prevezer, W, \& Venus, P. (2009). First Steps in Intervention with Your Child with Autism : Frameworks for Communication Retrieved from http://flinders.eblib.com/patron/FullRecord.aspx?p=465753

Crisman, Belinda W. (2008). Inclusive Programming for Students with Autism. Principal, 88(2), 28-32.

Dodd, S. (2005). Understanding autism. (Chapter 16, pp. 229-247). Marrickville, N.S.W.: Elsevier Australia 
Dunlop, A, Tait, C, Leask, A, Glashan, L, Robinson, A, \& Marwick, H. (2009). The autism toolbox: An autism resource for Scottish schools. Edinburgh: Scottish government.

Gabriel, R. (2002). Therapy: Laying the foundation for individual and family growth Autism : from research to individualized practice (pp. 91-126). London ; Philadelphia Jessica Kingsley Publishers.

Grandin, T. (1995). Teaching children with autism: strategies to enhance communication and socialization. Edited by Kathleen Ann Quill. Albany, N.Y.: Delmar Publishers, 1995. Chapter 2, pp. 33-52

Grether, S, \& Pelatti, C. (2010). Linking communication and literacy. In C. Christina \& W. Pamela (Eds.), Quality literacy instruction for students with Autism Spectrum Disorders. Shawnee Mission, Kansas: Autism Asperger Publishing Co.

Hamaguchi, P.M. (2010). Childhood speech, language and listening problems (3th Ed ed.). New Jersey: John Wiley \& Sons.

Huang, A., Wheeler, J. (2006). Effective interventions for individuals with high functional autism. International Journal of Special Education, 21(3)

Humphrey, N, \& Lewis, S. (2008). What does 'inclusion'mean for pupils on the autistic spectrum in mainstream secondary schools? Journal of Research in Special Educational Needs, 8(3), 132-140.

Jordan, R. (2004). Meeting the needs of children with autistic spectrum disorders in the early years. Australian Journal of Early Childhood, 29(3), 1-7.

Keane, E, Aldridge, F, Costley, D, \& Clark, T. (2012). Students with autism in regular classes: a long-term follow-up study of a satellite class transition model. International journal of inclusive education, 16(10), 1001-1017.

Kelley, E. (2011). Language in ASD. In D. Fein (Ed.), Neuropsychology of Autism (pp. 123-133). New York: Oxford University Press.

Lawson, Wendy. (2001). Key to understand the spectrum of autism Understanding and Working With the Spectrum of Autism (pp. 29-54). London, Philadelphia: Jessica Kingsley Pub.

Lindgren, S., Doobay, A. (2011). Evidence based interventions for autism spectrum disorders., The University of Iowa

Marks, Susan Unok, Shaw-Hegwer, Jennifer, Schrader, Carl, Longaker, Tricia, Peters, Iris, Powers, Fran, \& Levine, Mark. (2003). Instructional management tips for teachers of students with autism spectrum disorder (ASD). Teaching exceptional children, 35(4), 50-55.

Reiter, S, \& Vitani, T. (2007). Inclusion of pupils with autism The effect of an intervention program on the regular pupils' burnout, attitudes and quality of mediation. Autism, 11(4), 321-333.

Smith, J, Donlan, J, \& Smith, B. (2012). Helping children with Autism Spectrum conditions through everyday transitions: small changes-big challenges

Tsaputra, A. (n.d). Inclusive education for children with disabilities in Indonesia: Dilemma and suitable framework for Indonesian context., pp. 1-8. Retrieved from

http://australiaawardsindo.or.id/files/arg/ARTICLE\%20FOR\%20ARG\%20BUL LETIN-ANTONI.pdf

Verdick, E., \& Reeve, E. (2012). The survival guide for kids with Autism Spectrum Disorders and their parents. Minneapolis: Free spirit publishing. 


\section{APPENDICES}

\section{Case Study}

Jack (pseudonym) is a six year old child with autism and a mild level of intellectual disability. He currently attends a pre-school setting and at the beginning of the next term he will begin school in a mainstream school classroom. Jack is developing speech and can communicate his needs in two to three word sentences. When feels anxious he may engage in echolalic speech, generally repeating the last word of the sentence spoken to him.

He is fascinated with most forms of transport, especially 'Thomas the Tank and Friends', and enjoys lining up toy trains, cars and trucks. He will play alongside other children quite happily and has been seen on occasions to 'drive' his cars into the play space where other children are building or playing imaginative games. Jack will articulate a few words about his activity. Jack enjoys looking at photographs of family members, his pet dog and the family cat, as well as books associated with transport. He is quite skilled at drawing, in particular, transport objects. Recently he has shown interest in using the computer to carry out basic designs of transport.

Jack can become distressed with larger groups of children. He will put his fingers in his ears, make hissing sounds and push any children who may come too close to him. There can be similar reactions when Jack is required to move from indoor to outdoor activities. This is an issue when considering his inclusion in a classroom setting. Jack has similar strong emotional reactions when asked to change activities, especially when he is focused on his special interests.

Jack's pre-school teachers consider that he is now ready to commence a reading program and are aware of the need to focus on comprehension. He is just beginning basic number concepts as well as writing numerals. He can write his name with some efforts as he appears unsure of where to start and finish the individual letters. Jack's pre-school teachers would like to develop strategies to assist the above academic areas before his transitions into the Grade 1 class.

Jack lives with his mother, father, nine-year-old sister and eight-year-old brother. His siblings attend the school into which Jack will have transition. The parents are very keen for Jack to be able to play simple games with his siblings as well as his school peers. Jack's parents are a little worried about the feelings of responsibility that their daughter appears to have for Jack when both are at school. She expresses a need to protect him during lunch and recess times, in case other students may bully him. 